\title{
Diversity and population structure of Plasmodium falciparum in Thailand based on the spatial and temporal haplotype patterns of the C-terminal 19-kDa domain of merozoite surface protein-1
}

Phumin Simpalipan', Sittiporn Pattaradilokrat', Napaporn Siripoon², Aree Seugorn², Morakot Kaewthamasorn³, Robert DJ Butcher ${ }^{4}$ and Pongchai Harnyuttanakorn ${ }^{1 *}$

\begin{abstract}
Background: The 19-kDa C-terminal region of the merozoite surface protein-1 of the human malaria parasite Plasmodium falciparum (PFMSP-1 ${ }_{19}$ ) constitutes the major component on the surface of merozoites and is considered as one of the leading candidates for asexual blood stage vaccines. Because the protein exhibits a level of sequence variation that may compromise the effectiveness of a vaccine, the global sequence diversity of PAMSP-1 ${ }_{19}$ has been subjected to extensive research, especially in malaria endemic areas. In Thailand, PfMSP- ${ }_{19}$ sequences have been derived from a single parasite population in Tak province, located along the Thailand-Myanmar border, since 1995. However, the extent of sequence variation and the spatiotemporal patterns of the MSP- ${ }_{19}$ haplotypes along the Thai borders with Laos and Cambodia are unknown.

Methods: Sixty-three isolates of $P$. falciparum from five geographically isolated populations along the Thai borders with Myanmar, Laos and Cambodia in three transmission seasons between 2002 and 2008 were collected and culture-adapted. The msp-1 gene block 17 was sequenced and analysed for the allelic diversity, frequency and distribution patterns of PfMSP-1 ${ }_{19}$ haplotypes in individual populations. The PfMSP-1 ${ }_{19}$ haplotype patterns were then compared between parasite populations to infer the population structure and genetic differentiation of the malaria parasite.

Results: Five conserved polymorphic positions, which accounted for five distinct haplotypes, of PfMSP-1 19 were identified. Differences in the prevalence of PAMSP-1 ${ }_{19}$ haplotypes were detected in different geographical regions, with the highest levels of genetic diversity being found in the Kanchanaburi and Ranong provinces along the Thailand-Myanmar border and Trat province located at the Thailand-Cambodia border. Despite this variability, the distribution patterns of individual PfMSP- ${ }_{19}$ haplotypes seemed to be very similar across the country and over the three malarial transmission seasons, suggesting that gene flow may operate between parasite populations circulating in Thailand and the three neighboring countries.
\end{abstract}

Conclusion: The major MSP-1 19 haplotypes of P. falciparum populations in all endemic populations during three transmission seasons in Thailand were identified, providing basic information on the common haplotypes of MSP-1 19 that is of use for malaria vaccine development and inferring the population structure of $P$. falciparum populations in Thailand.

Keywords: Allelic polymorphism, DNA sequencing, Merozoite surface antigen, Population structure, Southeast Asia

\footnotetext{
* Correspondence: hpongcha@chula.ac.th

'Department of Biology, Faculty of Science, Chulalongkorn University,

Bangkok 10330, Thailand

Full list of author information is available at the end of the article
}

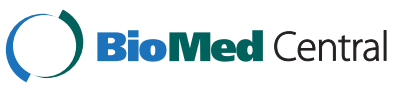

(c) 2014 Simpalipan et al.; licensee BioMed Central Ltd. This is an Open Access article distributed under the terms of the Creative Commons Attribution License (http://creativecommons.org/licenses/by/2.0), which permits unrestricted use, distribution, and reproduction in any medium, provided the original work is properly credited. The Creative Commons Public Domain Dedication waiver (http://creativecommons.org/publicdomain/zero/1.0/) applies to the data made available in this article, unless otherwise stated. 


\section{Background}

Because the clinical symptoms and pathology of malarial infections are caused by the erythrocytic stage cycles of the Plasmodium parasites [1-3], the development of a malaria vaccine targeting the asexual blood stage has a high priority in current malaria research. Safe and effective malaria vaccines are greatly needed in malaria endemic areas and could be used to supplement strategies of vector control and medical treatment for reducing the rates of morbidity and mortality [4]. The estimated number of malaria cases in 2012 was over 200 million with about 660,000 deaths [5], mostly in children under five years of age and pregnant women with heavy exposure to malaria infections. These numbers are, however, expected to increase due to treatment failure and/or delay in parasite clearance associated with the evolution and spread of drug-resistant malaria parasites [6]. To date, a small number of vaccines against the blood stage malaria parasites have been developed and a few of these are currently undergoing large-scale clinical trials $[7,8]$. Despite the fact that the majority of the vaccines have been shown to be safe and highly effective in animal models, immunizations with these blood stage malaria vaccines in humans was found to elicit allelic-specific anti-parasitic immunity [9-11], thereby compromising the efficacy of these vaccines. This is due to the allelic diversity of the strongly antigenic portions used as candidate vaccine antigens in the natural parasite populations, which poses one of the major challenges to development of effective vaccines. Thus, it is essential to investigate the extent of the genetic variation of malarial antigens and the population structure of malaria parasites in nature so that a better malaria vaccine, such as those that incorporate multiple variants of protective antigens can be properly designed. Alternatively, the development of malaria vaccines based on the conserved epitopes of antigens, if they are sufficiently antigenic and so elicit protective immunity, would offer an alternative strategy.

Components of blood stage malaria vaccines are generally derived from parasite ligands (antigens) expressed on the surface of merozoites, the only extracellular blood stage parasite. Among them is the merozoite surface protein-1 (MSP-1) that is currently used as a major component of anti-blood stage human malaria vaccines $[12,13]$. The gene encoding MSP-1 of the human malaria parasite Plasmodium falciparum spans $\sim 5 \mathrm{~kb}$ in size on chromosome 9 and can be divided into 17 blocks, according to the presence or absence of $9 \mathrm{bp}$ repeats and the type of repeating sequences $[14,15]$. The nucleotide sequences of the $m s p-1$ gene are classified into two allelic types: K1 and MAD20, with the exception of the highly polymorphic block 2 that is represented by at least three allelic types (K1, MAD20 and RO33) [16]. The MSP-1 protein is initially synthesized as a $190 \mathrm{kDa}$ or $195 \mathrm{kDa}$ polypeptide
[17]. During the beginning of merozoite invasion into the host's erythrocyte, the protein undergoes primary proteolytic cleavage events to generate four fragments of $83 \mathrm{kDa}\left(\mathrm{MSP}-1_{83}\right), 30 \mathrm{kDa}\left(\mathrm{MSP}-1_{30}\right), 38 \mathrm{kDa}\left(\mathrm{MSP}-1_{38}\right)$ and $42 \mathrm{kDa}\left(\mathrm{MSP}^{-1} \mathrm{1}_{42}\right)[18,19]$. These fragments are held together as a complex and attached to the parasite's surface via a glycosylphosphatidylinositol anchor. At the point of merozoite invasion, the MSP- $1_{42}$ fragment is proteolytically processed to form the $33 \mathrm{kDa}\left(\mathrm{MSP}-1_{33}\right)$ and $19 \mathrm{kDa}\left(\mathrm{MSP}_{-1} \mathrm{1}_{19}\right)$ fragments [20]. The MSP- $1_{19}$ fragment, containing two epidermal growth factor (EGF)-like domains, remains attached to the parasite's surface [21].

Two coding regions of the $m s p-1$ gene (blocks 2 and 17) have been identified to be prime targets of protective immunity. Previous studies have indicated that natural clinical immunity against blood malaria infections targets the N-terminal fragments encoded by block 2 of $m s p-1$ gene in an allelic-type specific manner [22-24]. Naturally acquired antibodies to the C-terminal MSP- $1_{19}$, encoded by block 17 of the $m s p-1$ gene, could also inhibit erythrocyte invasion by preventing the secondary processing that released MSP- $_{19}$ from the rest of the MSP-1 complex $[20,25]$. Invasion-inhibiting antibodies against $M S P-1_{19}$ have been detected in the sera from individuals living in areas that the highly endemic for malaria and were associated with protection from clinical malaria [26-33]. As mentioned, a few MSP- $1_{19}$-based vaccines are currently in Phase I and Phase II clinical trials in humans and so far have been shown to be safe and immunogenic [34-36].

Polymorphism in the $P$. falciparum $m s p-1$ gene block 17 sequences has been fairly extensively researched and they have been classified into at least 10 MSP-1 19 haplotypes in natural populations of P. falciparum [37-51]. Of these, four major haplotypes (Q/KNG/L, E/KNG/L, $\mathrm{Q} / \mathrm{KNG} / \mathrm{L}$ and $\mathrm{E} / \mathrm{TSR} / \mathrm{L}$ ) have been frequently identified in multiple malaria endemic regions. Comparisons of the distribution patterns and frequencies of MSP- $1_{19}$ haplotypes among different parasite populations revealed that the populations of $P$. falciparum are genetically diverse [46], consistent with the observations based upon the largescale genome-wide sequencing-based and microarray-based genotyping data [52,53]. In addition, PfMSP- $1_{19}$ haplotypes can also be utilized to infer the population structure of $P$. falciparum parasites. A recent study indicated the subdivision of two $P$. falciparum populations in China according to their variations in the distribution patterns of MSP- $1_{19}$ haplotypes, where the parasite populations in Yunnan (South China) appeared to be more closely related to the parasite populations in Southeast Asia (Thailand and Vietnam) than those in Hainan Island located on the South China Sea [46]. The shared distribution pattern of the haplotypes is consistent with the fact that many reported cases in Yunnan were imported malaria from border areas, suggesting an 
impediment in the gene flow between the regions in mainland Indochina [54].

Recently, the emergence of artemisinin resistance in $P$. falciparum has been reported in Southeast Asia and has drawn the global attention to the need for improvement in malaria intervention [55,56]. After the first report incidence of artemisinin resistance in $P$. falciparum at the Thailand-Cambodian border in 2008 [57], artemisinin resistance has now been reported on the western border of Thailand close to Myanmar [58]. Because of this spread of artemisinin resistance, it is of great interest to investigate the genetic composition and population structure of Thai $P$. falciparum isolates at these localities. In Thailand, much of the current knowledge of the $m s p-1$ sequence diversity originated from the analyses of a single parasite population at Mea Sod, Tak province at the Thai-Myanmar border $[38,39,51]$, but little work has been done to further elucidate the level of genetic diversity in other regions of the country, especially where the artemisinin resistant parasites are likely to spread. To address this issue, a cross-sectional survey of the allelic diversity of the $m s p-1$ gene block 17 in five geographically isolated populations of P. falciparum in Thailand was performed in order to infer the genetic structure of the parasite populations from the distribution patterns of their MSP- $1_{19}$ haplotypes. The outcome of this work will shed light on the nature and genetic relationship within and between malaria populations and offer a chance to better understand the parasite's evolution, which will be important for establishing an effective strategy for malaria control and intervention.

\section{Methods}

\section{Studied areas and preparation of parasites}

Field isolates of $P$. falciparum were collected from five localities (1-5), each in a different province, close to the borders of Thailand and three neighbouring countries. These were (1) Ubon Ratchathani, located at the Thailand-Laos border, (2) Trat, located at the Thailand-Cambodia border, and (3-5) Ranong, Kanchanaburi and Mae Hong Son, located at the Thailand-Myanmar border. The subjects were confirmed for P. falciparum mono-infection by microscopic examination of Giemsa-stained blood smears. The subjects were recruited in three transmission seasons between: (1) Jun 2002-Oct 2003, (2) Jun 2004-Dec 2005 but also including one subject in 2006 and (3) Jan 2008-Dec 2008 (see Additional file 1). Sixty-three blood stage malaria samples were adapted to in vitro culture and maintained at the Malaria Research Unit, Department of Biology, Faculty of Science, Chulalongkorn University, Thailand, as described previously [59]. Of these, 44 samples collected between 2002 and 2006 were previously genotyped by 12 microsatellite loci and confirmed to be independent clones [59] (see Additional file 1). In brief, the blood stage parasites were cultured in RPMI 1640 medium containing $25 \mathrm{mM}$ HEPES, 4\% (v/v) human blood group O erythrocytes (4\% haematocrit), 10\% (v/v) pooled heat-inactivated serum from healthy donors, $24 \mathrm{mM}$ sodium bicarbonate and $10 \mu \mathrm{g} / \mathrm{mL}$ gentamycin at $37^{\circ} \mathrm{C}$ with $5 \%(\mathrm{v} / \mathrm{v}) \mathrm{CO}_{2}, 5 \%(\mathrm{v} / \mathrm{v}) \mathrm{O}_{2}$ and $90 \%(\mathrm{v} / \mathrm{v}) \mathrm{N}_{2}$. The medium was changed daily, and the parasites were allowed to grow to a parasitaemia level of $5-10 \%$ and then harvested prior to genomic DNA preparation.

\section{Preparation of $P$. falciparum genomic DNA}

Procedures for preparation of the blood stage malaria parasites and genomic DNA were performed as previously described [60,61]. Briefly, P. falciparum infected blood samples were centrifuged at $5,000 \mathrm{~g}$ and the supernatant was discarded. Then, a $200 \mu \mathrm{L}$ volume of the packed blood cells was mixed with $500 \mu \mathrm{L}$ of $0.05 \%$ (w/v) saponin solution in phosphate buffered saline (PBS, $\mathrm{pH} 7.4$ ) to release the blood stage malaria parasites from the human erythrocytes. The parasite pellets were collected by centrifugation at $10,000 \mathrm{~g}$ for $10 \mathrm{~min}$ and washed twice in PBS. The parasites were lysed in a lysis solution $(40 \mathrm{mM}$ Tris- $\mathrm{HCl}$, $80 \mathrm{mM}$ EDTA, 2\% (w/v) sodium dodecyl sulfate, $\mathrm{pH}$ 8.0) containing $2 \mathrm{mg} / \mathrm{mL}$ proteinase $\mathrm{K}$. The suspension was sequentially treated with an equal volume of phenol (pH 8.0), phenol/chloroform/isoamyl alcohol (25:24:1 $(\mathrm{v} / \mathrm{v} / \mathrm{v}), \mathrm{pH}$ 8.0) and chloroform, harvesting the aqueous phase each time. The genomic DNA was then recovered by ethanol precipitation in the presence of $0.3 \mathrm{M}$ sodium acetate and later dissolved in standard TE buffer $(10 \mathrm{mM}$ Tris- $\mathrm{HCl}, 1 \mathrm{mM}$ EDTA, $\mathrm{pH}$ 8.0) and stored at $-20^{\circ} \mathrm{C}$ prior to PCR amplification.

\section{Amplification and DNA sequencing of the $P$. falciparum msp-1 gene block 17}

A DNA fragment corresponding to the $m s p-1$ gene block 17 was amplified by the polymerase chain reaction (PCR) with the MM1/17F (5' -TCACAACACCAATGCGTAAA A-3') and MM1/17R (5'-GAGTATTAATAAGAATGATA TTCCTAAG-3') primer pair, which correspond to nucleotide positions $4,825-4,845$ and 5,136-5,109 of the coding sequence of the msp- 1 gene of the P. falciparum strain 3D7 (NCBI accession number: XM_001352134, [62]). The PCR amplification reactions were performed in a $50 \mu \mathrm{L}$ volume containing 200-300 ng of DNA template, $2 \mathrm{mM}$ of $\mathrm{MgCl}_{2}, 200 \mu \mathrm{M}$ of each dNTP, $0.5 \mu \mathrm{M}$ each of the forward and reverse primers and 2 units (U) of $\mathrm{iTaq}^{\text {sm }}$-DNA polymerase enzyme in $1 \mathrm{X}$ iTaq PCR buffer (iNtRON Biotechnology, Republic of Korea). Thermal cycling was performed with an optimized profile of an initial denaturation at $95^{\circ} \mathrm{C}$ for $5 \mathrm{~min}$, followed by 30 cycles of $95^{\circ} \mathrm{C}$ for $40 \mathrm{~s}, 53^{\circ} \mathrm{C}$ for $40 \mathrm{~s}$ and $72^{\circ} \mathrm{C}$ for $40 \mathrm{~s}$, and subsequently a final extension at $72^{\circ} \mathrm{C}$ for $5 \mathrm{~min}$. PCR products were analysed by standard gel electrophoresis, stained with ethidium bromide and visualized by UV 
transillumination. All 63 samples generated single amplicons with an expected size of $220 \mathrm{bp}$, and were subjected to direct Sanger DNA sequencing in both the forward and reverse directions to ensure the accuracy of obtained sequences. Sequencing reactions were performed using the BigDye Terminator v1.1 kit (Applied Biosystems, USA) with an ABI3730 DNA analyser. DNA sequences were manually edited using Bioedit 7.0.0 software and aligned using the MUSCLE Sequence Alignment algorithm in the MEGA 5.2 program [63]. In total, 61 DNA samples generated unambiguous sequences in both directions and were used in the subsequent population genetic analysis.

\section{DNA sequence analysis and statistical analysis}

The predicted amino acid sequences of the C-terminal fragment of PfMSP- $1_{19}$ from the PCR sequenced genomic fragments were aligned with the corresponding sequence of the $P$. falciparum genome reference strain 3D7 using the MUSCLE Sequence Alignment algorithms as above. The extent of genetic diversity was estimated by the number and ratio of $\mathrm{MSP}-1_{19}$ haplotypes prevalent in the populations. Divergences in the distribution pattern of PfMSP-1 19 haplotypes between two parasite populations was tested for using the Wright's fixation index $\left(\mathrm{F}_{\mathrm{st}}\right)$ with Arlequin suite version 3.5 [64]. In addition, the departure from the predictions of the neutral mode of molecular evolution was evaluated using three neutrality tests (Tajima's D, Fu \& Li's $D^{*}$ and Fu \& Li's F*indices) implement in the DnaSP 5.1 program [65]. Results were deemed to be statistically significant if the $p$ value was less than $0.05(p<0.05)$.

\section{Results}

\section{Sequence diversity of msp-1 gene block 17}

Nucleotide sequences of $P$. falciparum $m s p-1$ gene block 17 (corresponding to nucleotide positions 4990 to 5208 after Tanabe et al. [15]) encoding the C-terminal fragment of the MSP-1 protein (MSP-1 19 , amino acid positions 1644 to 1716 after Miller et al. [14]) were obtained from 61 parasite isolates from five geographical locations in Thailand between 2002 and 2008, as described in the Materials and Methods. Five polymorphic sites $(2.28 \%$ of the $219 \mathrm{nt}$. fragments analysed) at nucleotide positions $4990 \mathrm{G} / \mathrm{C}, 5132 \mathrm{C} / \mathrm{A}, 5159 \mathrm{G} / \mathrm{A}, 5161 \mathrm{G} / \mathrm{A}$ and 5206 C/T were detected (see Additional file 2 for the sequence alignment). The nucleotide substitution frequency at positions 4990, 5132, 5159, 5161 and 5206 was G/C (43/18;70.5/ 29.5\%), C/A (10/51; 16.4/83.6\%), G/A (51/10; 83.6/16.4\%), G/A (55/6; 90.2/9.8\%) and C/T (58/3; 95/5\%), respectively. These nucleotide substitutions results in non-synonmous amino acid substitutions at positions 1644 E (GAA)/ Q (CAA), $1691 \mathrm{~T}$ (ACA)/K (AAA), $1700 \mathrm{~S}(\mathrm{AGC}) / \mathrm{N}(\mathrm{A} A \mathrm{C})$, $1701 \mathrm{G}(\mathrm{GGA}) / \mathrm{R}(A \mathrm{GA})$ and $1716 \mathrm{~L}(\mathrm{CTT}) / \mathrm{F}(T \mathrm{TT})$ (the italicized letter indicated the polymorphic site). The frequency of amino acid substitutions at each site was E1664Q (43/18; 70/30\%), T1691K (10/51; 16/84\%), S1700N (10/51; 16/84\%), R1701G $(6 / 55 ; 10 / 90 \%)$ and L1716F (58/3; 95/5\%). The PfMSP- $1_{19}$ fragment contained nine conserved Cys residues. The first amino acid substitution (E1664Q) was located between the second and the third Cys residues in the first putative EGF-like motif, while the other substitutions occurred in the second EGF-like motif of PfMSP- $1_{19}$ (Figure 1). Therefore, the PfMSP-1 19 amino acid sequences yielded five distinct haplotypes: E/KNG/L, E/TSR/L, Q/KNG/L, E/TSG/L (3D7 type) and $\mathrm{Q} / \mathrm{KNG} / \mathrm{F}$, all of which have been reported previously [37-51].

\section{Prevalence and distribution patterns of MSP-1 ${ }_{19}$ in geographically isolated Thai $P$. falciparum populations}

Figure 2 shows the overall prevalence and distribution pattern of PfMSP-1 19 haplotypes in the five geographical locations of Mae Hong Son $(n=9)$, Kanchanaburi $(n=15)$ and Ranong $(n=14)$, located at the Thailand-Myanmar border, Ubon Ratchathani $(\mathrm{n}=12)$ located at the ThailandLaos border, and Trat $(n=11)$, located at the ThailandCambodia border (see also Additional file 1). Of the five haplotypes identified, E/KNG/L, Q/KNG/L and E/TSR/L were the most prevalent and were found in all sampled sites, representing 57\%, 23\% and 11\% of the overall haplotypes investigated, respectively.

These results also revealed that there were slight differences in the levels of genetic diversity, based upon the number of PAMSP-1 19 haplotypes, among the different geographical populations (Figure 2). P. falciparum populations in Mae Hong Son and Ubon Ratchathani were the least genetically diverse group of parasites, with only three haplotypes identified. E/KNG/L was the major PfMSP-1 19 haplotype at both sites, and represented $75-78 \%$ of the total haplotypes. In contrast, all the five PfMSP $-1_{19}$ haplotypes were prevalent in the other three $P$. falciparum populations. Only in Trat was four haplotypes (all except for haplotype $\mathrm{Q} / \mathrm{KNG} / \mathrm{F}$ ) identified. In these three sites, the E/KNG/L, Q/KNG/L and E/TSR/L haplotypes constituted more than $80 \%$ of the total haplotypes investigated. Thus, the level of genetic diversity varied according to the geographical location of the parasite populations, which might reflect variation in the transmission intensity and multiplicity of human malaria infections between sampling sites [66].

To further determine whether the geographically isolated parasite populations are genetically isolated, pair-wise interpopulation comparisons were performed for each parasite population using the Wright's fixation index $\left(\mathrm{F}_{\mathrm{st}}\right)$. In this test, the distribution patterns of PAMSP-1 $1_{19}$ haplotypes in Tak province (collected in 1995), which is located between Kanchanaburi (the region in which the parasite genetic 


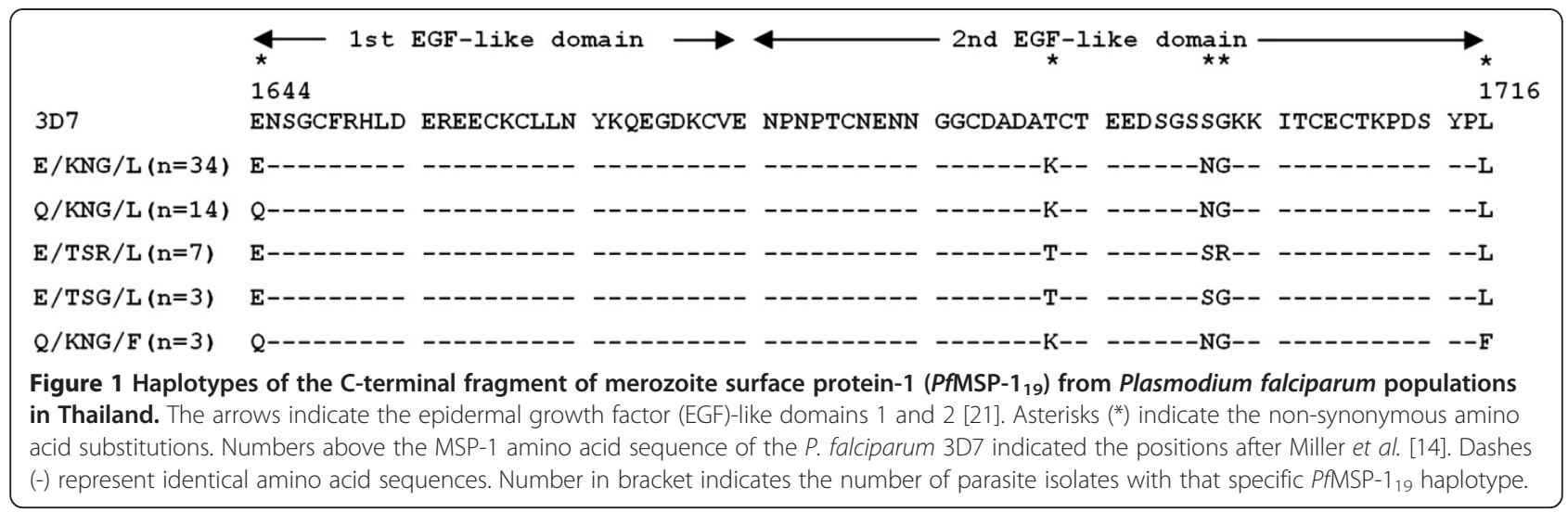

diversity was highest) and Mae Hong Son (the region in which the parasite genetic diversity was lowest), from two previous studies were also included. One consisted of 8 $\mathrm{E} / \mathrm{TSR} / \mathrm{L}, 25 \mathrm{E} / \mathrm{KNG} / \mathrm{L}, 12 \mathrm{Q} / \mathrm{KNG} / \mathrm{L}$ and $3 \mathrm{Q} / \mathrm{KNG} / \mathrm{F}$ haplotypes (total $=48)$ [39], while the other comprised 14. E/TSR/L, $39 \mathrm{E} / \mathrm{KNG} / \mathrm{L}, 13 \mathrm{Q} / \mathrm{KNG} / \mathrm{L}, 4 \mathrm{Q} / \mathrm{KNG} / \mathrm{F}$ and $2 \mathrm{E} / \mathrm{TSG} / \mathrm{L}$ haplotypes (total $=72$ ) [38]. As shown in Table 1, the $F_{\text {st }}$ values from the pairs of all the six parasite populations were low and non-significant $(p>0.05)$. Accordingly, the P. falciparum parasite populations (or at least the PfMSP-1 19 ) circulating in this region are genetically homogeneous, suggesting gene flow between allopatric populations of the malaria parasites near the borders of Thailand with Myanmar, Laos and Cambodia.

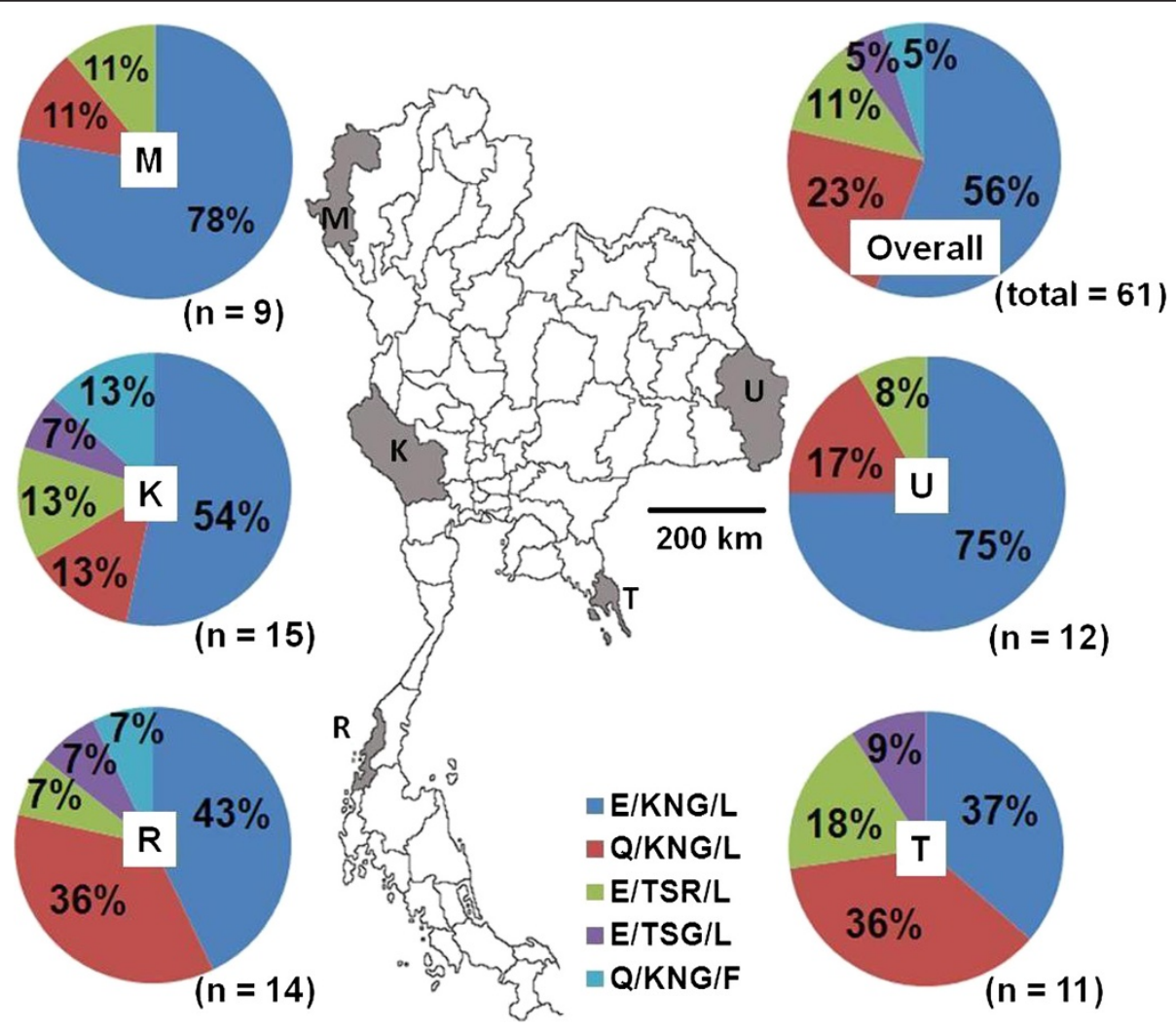

Figure 2 Allelic diversity of the C-terminal fragment of $P f \mathrm{MSP}-1_{19}$ in Plasmodium falciparum populations in Thailand. Sampling sites were at the borders of Thailand and three neighboring countries: Ubon Ratchathani (U), located at the Laos-Thailand border, Trat (T), located at the Cambodian-Thailand border, and Mae Hong Son (M), Kanchanaburi (K) and Ranong (R), located at the Myanmar-Thailand border. Numbers (n) of the total parasite isolates in Thailand (overall) or the parasites from each locality are displayed in the bracket. Numbers in pie charts represent the percentage of each MSP-1 19 haplotype (E/KNG/L, dark blue; Q/KNG/L, red; E/TSR/L, green; E/TSG/L, purple; QKNG/F, light blue). 
Table 1 Pairwise $F_{s t}$ values of PfMSP-1 19 haplotypes between geographically isolated Plasmodium falciparum populations in Thailand

\begin{tabular}{|c|c|c|c|c|c|}
\hline & Mae Hong Son & Ubon Ratchathani & Kanchanaburi & Trat & Ranong \\
\hline \multirow[t]{2}{*}{ Ubon Ratchathani } & -0.09985 & - & & & \\
\hline & $(p=0.99)$ & & & & \\
\hline \multirow[t]{2}{*}{ Kanchanaburi } & -0.04761 & -0.02984 & - & & \\
\hline & $(p=0.77)$ & $(p=0.56)$ & & & \\
\hline \multirow[t]{2}{*}{ Trat } & -0.01113 & 0.01017 & -0.05754 & - & \\
\hline & $(p=0.41)$ & $(p=0.23)$ & $(p=0.73)$ & & \\
\hline \multirow[t]{2}{*}{ Ranong } & 0.00241 & -0.00344 & -0.04347 & -0.04642 & - \\
\hline & $(p=0.42)$ & $(p=0.39)$ & $(p=0.72)$ & $(p=0.74)$ & \\
\hline \multirow[t]{2}{*}{ Tak $^{*}$} & -0.02637 & -0.01682 & -0.03795 & -0.03720 & -0.02997 \\
\hline & $(p=0.51)$ & $(p=0.55)$ & $(p=0.89)$ & $(p=0.67)$ & $(p=0.71)$ \\
\hline \multirow[t]{2}{*}{$T a k^{* *}$} & -0.02075 & -0.00632 & -0.02612 & -0.01521 & -0.0010 \\
\hline & $(p=0.4$ & $(p=0.46)$ & $(p=0.89)$ & $(p=0.66)$ & $(p=0.71)$ \\
\hline
\end{tabular}

Frequency of the PfMSP-1 19 haplotypes in Tak were derived from two studies by $\left(^{*}\right)$ Sakihama et al., [38] and $(* *)$ Sakihama et al., [39]. All $\mathrm{F}_{\text {st }}$ values were non-significant $(p>0.05)$.

\section{Conserved patterns of MSP-1 19 haplotypes in three} transmission seasons

The prevalence of MSP-1 19 haplotypes in three transmission seasons is shown in Figure 3. Of the $61 \mathrm{msp}-1$ sequences analysed, 21 sequences were obtained in a 15-month period between Jun 2002-Oct 2003 and contained three haplotypes (E/KNG/L, E/TSR/L and Q/ KNG/L); 25 sequences were obtained in an 18-month period between Jun 2004-Dec 2005 (plus one sample collected in early 2006) and contained all five haplotypes; and 15 sequences were collected in a 12-month period between Jan-Dec 2008. As seen in Figure 3, the E/KNG/L and $\mathrm{Q} / \mathrm{KNG} / \mathrm{L}$ haplotypes were the two most prevalent haplotypes in all three seasons, with cumulative frequencies of $60-80 \%$ of the haplotypes identified throughout the

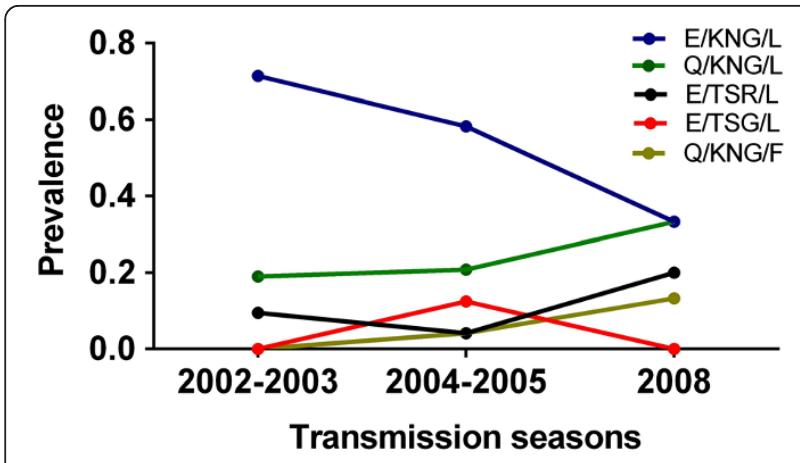

Figure 3 Prevalence of the C-terminal fragments of PfMSP-1 19 in Thai Plasmodium falciparum populations over time. $P$. falciparum samples were collected in three transmission seasons: Jun 2002-Oct 2003, Jun 2004-Dec 2005 (but including one sample collected in 2006, see Materials and Methods) and Jan 2008-Dec 20008. MSP-1 19 haplotypes: E/KNG/L, blue; Q/KNG/L, green; E/TSR/L, black; E/TSG/L, red; $\mathrm{Q} / \mathrm{KNG} / \mathrm{F}$, yellow. study years. However, over this time period the E/KNG/L haplotype decreased in frequency whilst the $\mathrm{Q} / \mathrm{KNG} / \mathrm{L}$ haplotype increased, with the relative $\mathrm{E} / \mathrm{KNG} / \mathrm{L}: \mathrm{Q} / \mathrm{KNG} / \mathrm{L}$ proportion changing from 3.5:1 in Jun 2002-Oct 2003 to 1:1 in Jan 2008-Dec 2008, indicating longitudinal variation in the frequencies of the prevalent haplotypes. In contrast, the frequencies of each of the three minor haplotypes remained low (>10\%) and relatively stable throughout the three-year period.

Pair-wise inter-population comparison of the PfMSP- $1_{19}$ haplotypes between years was compared using the Wright's fixation index $\left(\mathrm{F}_{\mathrm{st}}\right)$, and this revealed low and nonsignificant $\mathrm{F}_{\mathrm{st}}$ values $(p>0.05)$ (Table 2$)$, suggesting a similar MSP- $1_{19}$ haplotype distribution between the parasite populations in successive years. Furthermore, when the haplotypes of MSP- $1_{19}$ from Tak province (collected in 1995 [38,39]) was included in the analysis, the results also revealed a similar haplotype distribution in 1995 and the other study periods (see Table 2). Thus, the frequencies of the individual haplotypes were potentially stable during the four transmission seasons.

\section{Selection signature on msp-1 gene block 17 locus}

The geographically separate and so potentially isolated populations of $P$. falciparum in Thailand were found to not be significantly heterogeneous at the PfMSP-1 19 locus, suggesting that the different PfMSP-1 19 haplotypes may be maintained by balancing selection. Therefore, intrapopulation based analyses (Tajima's D test, Fu \& Li's $D^{*}$ test and $\mathrm{Fu} \&$ Li's $F^{*}$ test) were used to evaluate the selection signature on the PfMSP-1 19 locus. No significant positive D value (Tajima'D $=0.4082$; Fu \& Li's $D^{*}=1.079$ and Fu \& Li's $\left.F^{*}=1.016\right)$ was found for the entire block 17 coding region. In addition, although a sliding window analyses of Tajima's 
Table 2 Pairwise $F_{\text {st }}$ values of PfMSP-1 19 haplotypes in Plasmodium falciparum populations in the sampling years 1995, 2002-2003, 2004-2005 and 2008

\begin{tabular}{lllll}
\hline & Population in 1995* & Population in 1995** & Population in Jun 02-Oct 03 & Population in Jun 04-Dec 05 \\
\hline Population in Jun 02-Oct 03 & 0.00575 & -0.00694 & $*$ & \\
& $(p=0.30)$ & $(p=0.40)$ & & \\
Population in Jun 04-Dec 05 & -0.00268 & -0.01639 & -0.02722 & \\
& $(p=0.92)$ & $(p=0.71)$ & $(p=0.73)$ & 0.00518 \\
Population in Jan 08-Dec 08 & 0.02685 & -0.02287 & 0.04219 & $(p=0.30)$ \\
& $(p=0.16)$ & $(p=0.59)$ & $(p=0.14)$ & \\
\hline
\end{tabular}

Frequency of the PfMSP- $1_{19}$ haplotypes in 1995 were from two studies by $(*)$ Sakihama et al., [38] and $\left(^{* *}\right)$ Sakihama et al., [39]. All $F_{s t}$ values were non-significant $(p>0.05)$.

D test, Fu \& Li's $D^{*}$ test and Fu \& Li's $F^{*}$ test revealed positive D values for the EGF-1 and EGF-2 domains, they were not statistically significant (Figure 4). A comparison of the ratio of synonymous to non-synonymous substitutions $\left(\mathrm{K}_{\mathrm{a}} / \mathrm{K}_{\mathrm{s}}\right)$ was not analysed because the number of synonymous differences $\left(\mathrm{K}_{\mathrm{s}}\right)$ was too low (zero). Overall, the polymorphisms at the C-terminal fragment of the $m s p$ - 1 gene block 17 were less likely to be under strong immune selection, suggesting a functional constraint that limits the allelic diversity of the sequences. Taken together, the polymorphisms detected in PfMSP-1 19 were neutral and highly conserved in the geographically isolated, but genetically homogenous $P$. falciparum populations in Thailand.

\section{Discussion}

The 19-kDa antigenic domain of PAMSP-1 is considered the major target component for the developmetn of human blood stage malaria vaccines [13]. Therefore, the analysis of the sequence diversity of the $m s p-1$ gene block 17 that encodes PfMSP-1 19 has gained considerable attention in the global malaria research community, leading to the identification of its polymorphism level and haplotypes [37-51]. PfMSP- $1_{19}$ sequences have been primarily classified into two prototypic allelic groups: (1) the MAD20 prototypic allelic group (E/TSR/L haplotype) and (2) the Wellcome prototype allelic group (Q/KNG/L haplotype) [15]. In addition, other variant haplotypes (E/KNG/L, $\mathrm{E} / \mathrm{TSG} / \mathrm{L}$ and $\mathrm{Q} / \mathrm{KNG} / \mathrm{F}$ ) have also been reported in natural populations of P. falciparum worldwide [37-51]. These haplotypes were proposed to be generated through recombination events between the two prototype alleles and due to mutations [42]. The analysis of PfMSP-1 19 sequence diversity in Thailand was previously conducted in a single locality in Tak, located on the western border of Thailand and identified at least five distinct haplotypes (E/KNG/L, E/TSR/L, Q/KNG/L, E/TSG/L and Q/KNG/F) [38]. However, it is not known whether the extent of PfMSP-1 19 sequence variation is common in other populations of $P$. falciparum in Thailand or whether the distribution pattern of these haplotypes is conserved. This question formed the basis of the present study, which aimed to screen for polymorphism and evaluate the haplotypes of the $m s p-1$ gene block 17 from different geographical regions in Thailand.

Nucleotide sequence analysis of the $m s p-1$ gene block 17 was performed on 61 Thai $P$. falciparum isolates originating from five endemic areas; Mea Hong Son, Kanchanaburi and Ranong, along the borders of Thailand and Myanmar, Trat at the border of Thailand and Cambodia, and Ubon Ratchathani, at the border of Thailand and Laos. These areas were among the top 15 provinces with the highest numbers of $P$. falciparum malaria cases in Thailand [67]. The five conserved polymorphic SNP sites that caused non-synonymous amino acid substitutions in the PfMSP- $1_{19}$ sequences (haplotypes E/KNG/L, E/TSR/L, Q/KNG/L, E/TSG/L and Q/KNG/F) previously

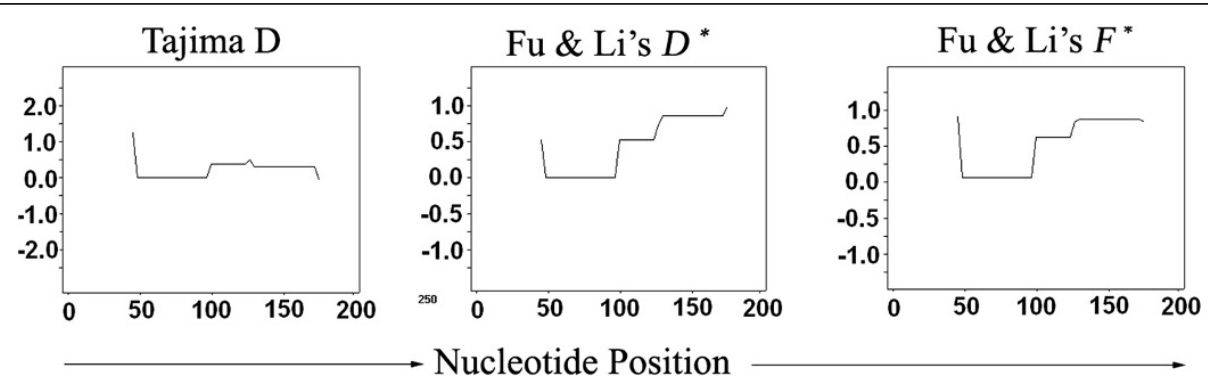

Figure 4 Sliding window plots of Tajima's $D$, Fu \& Li's $D^{*}$ and Fu \& Li's $F^{*}$ for the Pfmsp-1 gene block 17. Window length is 90 bp and step size is $3 \mathrm{bp}$. No evidence of a significant departure from neutrality or of diversifying selection was observed. 
identified in Tak $[38,39,51]$ and in other endemic regions worldwide [37,40-50], were found with no new haplotypes. Consistent with previous observations, these results reported here indicated that the allelic diversity of the $m s p-1$ gene block 17 in Thai $P$. falciparum populations was limited.

The levels of genetic diversity of the $m s p-1$ sequences in Thai populations varied according to the geographical locations. The lowest genetic diversity was detected in $P$. falciparum populations in Mae Hong Son and Ubon Ratchathani, with only three PfMSP- $1_{19}$ haplotypes of being found, compared to four and five in Kanchanaburi and Ranong, respectively. Variation in the levels of genetic diversity in geographically isolated populations may be due to variation in the multiplicity of infection, malaria incidence, transmission intensity and levels of gene flow between the parasite populations [59,66]. Malaria incidence rates showed a high spatial heterogeneity across the geographical regions in Thailand, with the highest rates in the regions near the borders of Thailand with Myanmar and Cambodia and lower rates in the regions near the Thailand-Laos border [68]. In addition, multiple or polyclonal infections with $P$. falciparum were highly prevalent at the Thailand-Myanmar border region in Kanchanaburi compared to at the Thailand-Laos borders [59]. Elevated levels of mixed genotype infections may well increase the frequency of recombination events of the msp- 1 alleles in the mosquito and subsequently a high diversity of $m s p-1$ would be maintained in Thai populations [66].

When the diversity and distribution patterns of MSP- $1_{19}$ haplotypes in Thai populations in the present study were compared with results from a previous study based upon microsatellite typing [59], no genetic differentiations was found between sub-populations in Mae Hong Son and Ubon Ratchathani, Mae Hong Son and Trat, Mae Hong Son and Ranong, Kanchanaburi and Ranong, and Ubon Ratchathani and Trat. However, the microsatellite analysis revealed a significant level of differentiation between subpopulations in Kanchanaburi and three other provinces (Mae Hong Son, Ubon Ratchathani and Trat), and in Ranong and two other provinces (Ubon Ratchathani and Trat). The discrepancy could be partly attributed to the differences in the sample size and the types of genetic markers used. Whether genetic differentiations exist in Thai sub-populations will require further investigations using a larger size of samples and additional markers, and this is an area of our current research.

The level of genetic differentiation of $P f \mathrm{MSP}-1_{19}$ in populations in Thailand, as detected using F-statistics $\left(\mathrm{F}_{\mathrm{st}}\right)$, revealed no significant differences between the $P$. falciparum populations located at the Thai borders with Myanmar, Laos and Cambodia. Accordingly, there may be no barriers that limit gene flow between geographically isolated P. falciparum populations in Thailand. This would likely reflect that there are numerous host (human) movements within and into Thailand from neighboring countries from immigrants who live across the borders [69,70]. For example, it was reported that in 2006 there were 30,338 malaria cases found in native Thais compared to 36,313 malaria cases from foreigners living in Thailand [71]. A cross-sectional survey showed that up to $75 \%$ of the malaria incidences in regions along the Thai borders were imported cases [67]. The majority of malaria-infected migrant workers were from Cambodia, Myanmar and Laos. Short-term and permanent migrations of infected humans, such as immigrant workers, may play a key role in the development and spread of anti-malaria drug resistance. This study also indicated that the Thai parasite populations along the three national borders are not genetically separated (and so may be mixed) and so are potentially subject to gene flow of novel phenotypes, most probably from Myanmar and Cambodia, where malaria transmission rates are high and multiclonal infections are prevalent. Gene flow within parasite populations may play an important role in shaping their population structure. Indeed, previous studies showed that the emergence of artemisinin resistance in P. falciparum occurred around the Thai-Cambodia border in 2009 and now has recently been found at the Thai-Myanmar border in 2011. The results from this study suggest that it is likely that the artemisinin resistant strains of $P$. falciparum could also spread to other regions of Thailand.

The longitudinal survey of MSP- $1_{19}$ haplotypes in four transmission seasons (from 1995 to 2008) revealed that the overall frequency of individual PfMSP- $1_{19}$ haplotypes was relatively stable, although the two major haplotypes $(\mathrm{E} / \mathrm{KNG} / \mathrm{L}$ and $\mathrm{Q} / \mathrm{KNG} / \mathrm{L})$ inversely fluctuated over time. This result was also seen in a previous longitudinal survey in Mali [44]. Comparison of the frequency of these PfMSP- $1_{19}$ haplotypes in endemic regions worldwide indicated a dramatic distribution pattern and frequency of PfMSP-1 $1_{19}$ haplotypes. The high prevalence of the $\mathrm{E} / \mathrm{KNG} / \mathrm{L}$ and $\mathrm{Q} / \mathrm{KNG} / \mathrm{L}$ haplotypes reported in Thailand has also been reported in the Yunan and Hainan provinces in China and Vietnam $[37,46]$, suggesting that P. falciparum populations in the Greater Mekong Sub-region (GMS) (China, Thailand, Laos, Myanmar, Cambodia and Vietnam) could be genetically related. Whether the parasite populations in GMS are genetically homogeneous will need to be evaluated by large-scale genotyping approaches using genome-wide genetic markers (e.g. microsatellites and SNPs, see [72]). Similar distribution patterns of PfMSP- $1_{19}$ in samples from the GMS have also been detected in African countries, such as Kenya, Tanzania and Mali [42-44]. In contrast, the three rare PfMSP- $1_{19}$ haplotypes (E/TSR/L, ETSG/L and Q/KNG/L) appeared to be the dominant haplotypes in other regions, such as South Asia (India and Iran), South America (Brazil 
and Peru), Vanatu and the Solomon Islands [39-41,50]. By providing information about the prevalence and spatiotemporal dynamics of $P f M S P-1_{19}$ haplotypes, this study could help inform choices about which $P$ PMSP- $1_{19}$ haplotypes to formulate future vaccines from and to allow a more accurate interpretation of the efficacy of current formulations of PfMSP- $1_{19}$ based vaccines being tested in clinical trials. Currently, MSP-1 sequences from $P$. falciparum $\mathrm{K} 1(\mathrm{Q} / \mathrm{KNG} / \mathrm{L})$ are being formulated as components of the multivalent blood stage vaccine PfCP-2.9 [35]. If the immunity conferred by such vaccines is allele specific, the PfCP-2.9 vaccine would be advantageous for populations in the GMS and in Africa, but not in South America and the Asian Pacific Islands.

It is possible that the limited allelic diversity in the MSP- $1_{19}$ sequences may be due to positive selection or balancing selection, as has been demonstrated for other regions of MSP-1 [22]. However, the Tajima's D test, Fu \& Li's $D^{\prime \prime}$ test and Fu \& Li's $F^{*}$ test all failed to reveal any statistically significant evidence for strong positive or balancing selection of the C-terminal fragments of PfMSP- $1_{19}$ in these Thai samples. The most probable explanation for the limited diversity in $P$ PMSP- $1_{19}$ is the functional constraint of the protein. MSP-1 is considered to play an important role in erythrocyte entry by the merozoite [13]. Secondary processing of PfMSP-1 to PfMSP- $1_{19}$ is a prerequisite for merozoite invasion [73]. The PfMSP- $1_{19}$ fragment possesses different epitopes and variation in the motifs alters the conformational structure markedly $[74,75]$. It may be that each motif has a unique association with other parts of MSP-1 and these differential intermolecular associations have implications in evading the host immune responses by masking the target epitopes in the 19-kDa domain [76]. Thus, selective constraints in the light of the host immune responses and functional constraints at the protein level may be co-operative to maintain the limited diversity of the MSP- $1_{19}$ amino acid sequences.

\section{Conclusion}

This study extends the understanding and current knowledge of the variation and prevalence of PfMSP- $1_{19}$ polymorphisms in natural populations of $P$. falciparum in Thailand. The data supports the view that $P$. falciparum populations in the GMS region are genetically diverse. Analysis of the spatiotemporal patterns of MSP-1 haplotypes indicated that $\mathrm{E} / \mathrm{KNG} / \mathrm{L}$ and $\mathrm{Q} / \mathrm{KNG} / \mathrm{L}$ were the major haplotypes in Thailand, which were also highly prevalent in populations from other Southeast Asian countries, China and Africa. This study provides the basis for the accurate measurement and interpretation of the population structure and dynamics of malaria parasites that is critical for monitoring the population responses to MSP-1 based vaccines in clinical trials.

\section{Additional files}

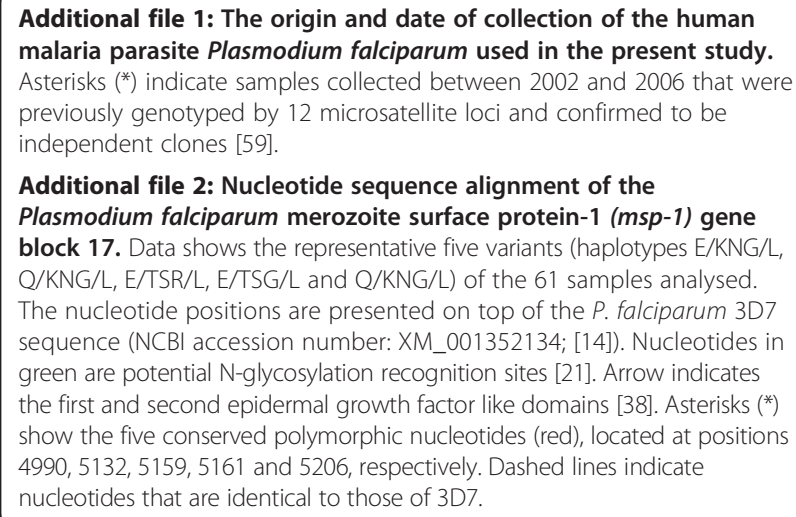

Competing interests

The authors declare that they have no competing interests.

\section{Authors' contributions}

PS carried out the molecular genetic work, interpretation of data and drafted the manuscript. SP performed data analysis and wrote the manuscript. NS and AS were responsible for parasite cultivation. MK and RB carried out the statistical analysis and guidance for data interpretation. $\mathrm{PH}$ provided conceptual framework for the project, guidance for the interpretation of data, participated in the manuscript preparation, revision and coordination. All authors read and approved the final manuscript.

\section{Acknowledgements}

This work was supported by grants from the National Research Council of Thailand to $\mathrm{PH}$, and from the Thai Government budget 2010 under the Research Program on Conservation and Utilization of Biodiversity and Center of Excellence in Biodiversity, Department of Biology Faculty of Science, Chulalongkorn University (CEB_M_49_2009) to PS. SP is a recipient of the Thailand Research Fund (TRF, MRG5680134) and a grant for development of new faculty staff, Chulalongkorn University (GDNS 56-064-23-017), Bangkok, Thailand.

\section{Author details}

${ }^{1}$ Department of Biology, Faculty of Science, Chulalongkorn University, Bangkok 10330, Thailand. ${ }^{2}$ College of Public Health Sciences, Chulalongkorn University, Bangkok 10330, Thailand. ${ }^{3}$ Department of Pathology, Faculty of Veterinary Science, Chulalongkorn University, Bangkok 10330, Thailand. ${ }^{4}$ Office of Research Affairs, Faculty of Science, Chulalongkorn University, Bangkok 10330, Thailand.

Received: 3 October 2013 Accepted: 27 January 2014 Published: 12 February 2014

\section{References}

1. Miller LH, Baruch DI, Marsh K, Doumbo OK: The pathogenic basis of malaria. Nature 2002, 415:673-679.

2. Cowman AF, Berry D, Baum J: The cellular and molecular basis for malaria parasite invasion of the human red blood cell. J Cell Biol 2012, 198:961-971.

3. Miller LH, Ackerman HC, Su XZ, Wellems TE: Malaria biology and disease pathogenesis: insights for new treatments. Nat Med 2013, 19:156-167.

4. Targett GA, Greenwood BM: Malaria vaccines and their potential role in the elimination of malaria. Malar J 2008, 7:S10.

5. WHO: World Malaria Report 2012. World Health Organization. Geneva. http://www.who.int/malaria/publications/world_malaria_report_2012/report/ en/index.html.

6. Sa JM, Chong JL, Wellems TE: Malaria drug resistance: new observations and developments. Essays Biochem 2011, 51:137-160.

7. Ellis RD, Sagara I, Doumbo O, Wu Y: Blood stage vaccines for Plasmodium falciparum: current status and the way forward. Hum Vaccin 2010, 6:627-634. 
8. Goodman AL, Draper SJ: Blood-stage malaria vaccines - recent progress and future challenges. Ann Trop Med Parasitol 2010, 104:189-211.

9. Genton B, Betuela I, Felger I, Al-Yaman F, Anders RF, Saul A, Rare L, Baisor M, Lorry K, Brown GV, Pye D, Irving DO, Smith TA, Beck HP, Alpers MP: A recombinant blood-stage malaria vaccine reduces Plasmodium falciparum density and exerts selective pressure on parasite populations in a phase 1-2b trial in Papua New Guinea. J Infect Dis 2002, 185:820-827.

10. Good MF, Stanisic D, Xu H, Elliott S, Wykes M: The immunological challenge to developing a vaccine to the blood stages of malaria parasites. Immunol Rev 2004, 201:254-267.

11. Genton B, Reed ZH: Asexual blood-stage malaria vaccine development: facing the challenges. Curr Opin Infect Dis 2007, 20:467-475.

12. Holder AA, Guevara Patino JA, Uthaipibull C, Syed SE, Ling IT, Scott-Finnigan T, Blackman MJ: Merozoite surface protein 1, immune evasion, and vaccines against asexual blood stage malaria. Parassitologia 1999, 41:409-414.

13. Holder AA: The carboxy-terminus of merozoite surface protein 1: structure, specific antibodies and immunity to malaria. Parasitology 2009, 136:1445-1456.

14. Miller LH, Roberts T, Shahabuddin M, McCutchan TF: Analysis of sequence diversity in the Plasmodium falciparum merozoite surface protein-1 (MSP-1). Mol Biochem Parasitol 1993, 59:1-14.

15. Tanabe K, Mackay M, Goman M, Scaife JG: Allelic dimorphism in a surface antigen gene of the malaria parasite Plasmodium falciparum. J Mol Biol 1987, 195:273-287.

16. Peterson MG, Coppel RL, Moloney MB, Kemp DJ: Third form of the precursor to the major merozoite surface antigens of Plasmodium falciparum. Mol Cell Biol 1988, 8:2664-2667.

17. McBride JS, Heidrich HG: Fragments of the polymorphic Mr 185,000 glycoprotein from the surface of isolated Plasmodium falciparum merozoites form an antigenic complex. Mol Biochem Parasitol 1987, 23:71-84.

18. Hall R, Osland A, Hyde JE, Simmons DL, Hope IA, Scaife JG: Processing, polymorphism, and biological significance of $\mathrm{P} 190$, a major surface antigen of the erythrocytic forms of Plasmodium falciparum. Mol Biochem Parasitol 1984, 11:61-80.

19. Holder AA, Sandhu JS, Hillman Y, Davey LS, Nicholls SC, Cooper H, Lockyer $\mathrm{MJ}$ : Processing of the precursor to the major merozoite surface antigens of Plasmodium falciparum. Parasitology 1987, 94:199-208.

20. Blackman MJ, Heidrich HG, Donachie S, McBride JS, Holder AA: A single fragment of a malaria merozoite surface protein remains on the parasite during red cell invasion and is the target of invasion-inhibiting antibodies. J Exp Med 1990, 172:379-382

21. Blackman MJ, Ling IT, Nicholls SC, Holder AA: Proteolytic processing of the Plasmodium falciparum merozoite surface protein-1 produces a membrane-bound fragment containing two epidermal growth factor-like domains. Mol Biochem Parasitol 1991, 49:29-33.

22. Conway DJ, Cavanagh DR, Tanabe K, Roper C, Mikes ZS, Sakihama N, Bojang KA, Oduola AM, Kremsner PG, Arnot DE, Greenwood BM, McBride JS: A principal target of human immunity to malaria identified by molecular population genetic and immunological analyses. Nat Med 2000, 6:689-692.

23. Polley SD, Tetteh KK, Cavanagh DR, Pearce RJ, Lloyd JM, Bojang KA, Okenu DM, Greenwood BM, McBride JS, Conway DJ: Repeat sequences in block 2 of Plasmodium falciparum merozoite surface protein 1 are targets of antibodies associated with protection from malaria. Infect Immun 2003, 71:1833-1842.

24. Cavanagh DR, Dodoo D, Hviid L, Kurtzhals JA, Theander TG, Akanmori BD, Polley S, Conway DJ, Koram K, McBride JS: Antibodies to the N-terminal block 2 of Plasmodium falciparum merozoite surface protein 1 are associated with protection against clinical malaria. Infect Immun 2004, 72:6492-6502.

25. Nwuba RI, Sodeinde O, Anumudu Cl, Omosun YO, Odaibo AB, Holder AA, Nwagwu M: The human immune response to Plasmodium falciparum includes both antibodies that inhibit merozoite surface protein 1 secondary processing and blocking antibodies. Infect Immun 2002, 70:5328-5331.

26. Branch $\mathrm{OH}$, Udhayakumar $\mathrm{V}$, Hightower AW, Oloo AJ, Hawley WA, Nahlen BL, Bloland PB, Kaslow DC, Lal AA: A longitudinal investigation of IgG and IgM antibody responses to the merozoite surface protein-1 19-kilodalton domain of Plasmodium falciparum in pregnant women and infants: Associations with febrile illness, parasitemia, and anemia. Am J Trop Med Hyg 1998, 58:211-219.

27. Branch $\mathrm{OH}$, Oloo AJ, Nahlen BL, Kaslow D, Lal AA: Anti-merozoite surface protein-1 19-kDa IgG in mother-infant pairs naturally exposed to Plasmodium falciparum: Subclass analysis with age, exposure to asexual parasitemia, and protection against malaria. V. The Asembo Bay Cohort Project. J Infect Dis 2000, 181:1746-1752.
28. Egan AF, Morris J, Barnish G, Allen S, Greenwood BM, Kaslow DC, Holder AA, Riley EM: Clinical immunity to Plasmodium falciparum malaria is associated with serum antibodies to the 19-kDa C-terminal fragment of the merozoite surface antigen, PfMSP-1. J Infect Dis 1996, 173:765-769.

29. John CC, O'Donnell RA, Sumba PO, Moormann AM, de Koning-Ward TF, King CL, Kazura JW, Crabb BS: Evidence that invasion-inhibitory antibodies specific for the 19-kDa fragment of merozoite surface protein-1 (MSP-1(19)) can play a protective role against blood-stage Plasmodium falciparum infection in individuals in a malaria endemic area of Africa. J Immuno/ 2004, 173:666-672.

30. Okech BA, Corran PH, Todd J, Joynson-Hicks A, Uthaipibull C, Egwang TG, Holder AA, Riley EM: Fine specificity of serum antibodies to Plasmodium falciparum merozoite surface protein, PfMSP-1(19), predicts protection from malaria infection and high-density parasitemia. Infect Immun 2004, 72:1557-1567.

31. Corran PH, O'Donnell RA, Todd J, Uthaipibull C, Holder AA, Crabb BS, Riley EM: The fine specificity, but not the invasion inhibitory activity, of 19kilodalton merozoite surface protein 1-specific antibodies is associated with resistance to malarial parasitemia in a cross-sectional survey in the Gambia. Infect Immun 2004, 72:6185-6189.

32. Omosun $\mathrm{YO}$, Adoro $\mathrm{S}$, Anumudu $\mathrm{Cl}$, Odaibo AB, Uthiapibull C, Holder AA, Nwagwu M, Nwuba Rl: Antibody specificities of children living in a malaria endemic area to inhibitory and blocking epitopes on MSP-1(19) of Plasmodium falciparum. Acta Trop 2009, 109:208-212.

33. Perraut R, Marrama L, Diouf B, Sokhna C, Tall A, Nabeth P, Trape JF, Trape FO, Longacre S, Mercereau-Puijalon O: Antibodies to the conserved Cterminal domain of the Plasmodium falciparum merozoite surface protein 1 and to the merozoite extract and their relationship with in vitro inhibitory antibodies and protection against clinical malaria in a Senegalese village. J Infect Dis 2005, 191:264-271.

34. Ogutu BR, Apollo OJ, McKinney D, Okoth W, Siangla J, Dubovsky F, Tucker K, Waitumbi JN, Diggs C, Wittes J, Malkin E, Leach A, Soisson LA, Milman JB, Otieno L, Holland CA, Polhemus M, Remich SA, Ockenhouse CF, Cohen J, Ballou WR, Martin SK, Angov E, Stewart VA, Lyon JA, Heppner DG, Withers MR, MSP-1 Malaria Vaccine Working Group: Blood stage malaria vaccine eliciting high antigen-specific antibody concentrations confers No protection to young children in western kenya. PLoS One 2009, 4:e4708.

35. Xue XY, Ding F, Zhang QF, Pan XG, Qu L, Pan WQ: Stability and potency of the Plasmodium falciparum MSP1-19/AMA-1 (III) chimeric vaccine candidate with Montanide ISA720 adjuvant. Vaccine 2010, 28:3152-3158.

36. Hu J, Chen Z, Gu J, Wan M, Shen Q, Kieny MP, He J, Li Z, Zhang Q, Reed ZH, Zhu Y, Li W, Cao Y, Qu L, Cao Z, Wang Q, Liu H, Pan X, Huang X, Zhang D, Xue $X$, Pan W: Safety and immunogenicity of a malaria vaccine, Plasmodium falciparum AMA-1/MSP-1 chimeric protein formulated in montanide ISA 720 in healthy adults. PLoS One 2008, 3:e1952.

37. Kaneko O, Kimura M, Kawamoto F, Ferreira MU, Tanabe K: Plasmodium falciparum: allelic variation in the merozoite surface protein 1 gene in wild isolates from southern Vietnam. Exp Parasitol 1997, 86:45-57.

38. Sakihama N, Kimura M, Hirayama K, Kanda T, Na-Bangchang K, Jongwutiwes S, Conway D, Tanabe K: Allelic recombination and linkage disequilibrium within Msp-1 of Plasmodium falciparum, the malignant human malaria parasite. Gene 1999, 230:47-54.

39. Sakihama N, Nakamura M, Palanca AA Jr, Argubano RA, Realon EP, Larracas $A L$, Espina $R L$, Tanabe $K$ : Allelic diversity in the merozoite surface protein 1 gene of Plasmodium falciparum on Palawan Island, the Philippines. Parasitol Int 2007, 56:185-194.

40. Mehrizi AA, Zakeri S, Salmanian AH, Sanati MH, Djadid ND: Plasmodium falciparum: sequence analysis of the gene encoding the C-terminus region of the merozoite surface protein-1, a potential malaria vaccine antigen, in Iranian clinical isolates. Exp Parasitol 2008, 118:378-385.

41. Da Silveira LA, Ribeiro WL, Kirchgatter K, Wunderlich G, Matsuoka H, Tanabe K, Ferreira MU: Sequence diversity and linkage disequilibrium within the merozoite surface protein-1 (Msp-1) locus of Plasmodium falciparum: a longitudinal study in Brazil. J Eukaryot Microbiol 2001, 48:433-439.

42. Qari SH, Shi YP, Goldman IF, Nahlen BL, Tibayrenc M, Lal AA: Predicted and observed alleles of Plasmodium falciparum merozoite surface protein-1 (MSP-1), a potential malaria vaccine antigen. Mol Biochem Parasitol 1998, 92:241-252.

43. Tanabe K, Sakihama N, Rooth I, Bjorkman A, Farnert A: High frequency of recombination-driven allelic diversity and temporal variation of Plasmodium falciparum msp1 in Tanzania. Am J Trop Med Hyg 2007, 76:1037-1045. 
44. Takala SL, Coulibaly D, Thera MA, Dicko A, Smith DL, Guindo AB, Kone AK, Traore K, Ouattara A, Djimde AA, Sehdev PS, Lyke KE, Diallo DA, Doumbo OK, Plowe CV: Dynamics of polymorphism in a malaria vaccine antigen at a vaccine-testing site in Mali. PLoS Med 2007, 4:e93.

45. Chenet SM, Branch OH, Escalante AA, Lucas CM, Bacon DJ: Genetic diversity of vaccine candidate antigens in Plasmodium falciparum isolates from the Amazon basin of Peru. Malaria J 2008, 7:93.

46. Pan D, Hu J, Ma Q, Pan W, Li M: Diversity and prevalence of the Cterminal region of Plasmodium falciparum merozoite surface protein 1 in China. Acta Trop 2010, 116:200-205.

47. Kang Y, Long CA: Sequence heterogeneity of the C-terminal, Cys-rich region of the merozoite surface protein-1 (MSP-1) in field samples of Plasmodium falciparum. Mol Biochem Parasitol 1995, 73:103-110.

48. Sakihama N, Ohmae H, Bakote'e B, Kawabata M, Hirayama K, Tanabe K: Limited allelic diversity of Plasmodium falciparum merozoite surface protein 1 gene from populations in the Solomon Islands. Am J Trop Med Hyg 2006, 74:31-40.

49. Ferreira MU, Ribeiro WL, Tonon AP, Kawamoto F, Rich SM: Sequence diversity and evolution of the malaria vaccine candidate merozoite surface protein-1 (MSP-1) of Plasmodium falciparum. Gene 2003, 304:65-75.

50. Vijay Kumar S, Ranjan S, Saxena V, Rajesh V, Roy SK, Kochar D, Ranjan A, Das A: Plasmodium falciparum: genetic diversity of C-terminal region of MSP-1 in isolates from Indian sub-continent. Exp Parasitol 2005, 110:384-388

51. Jongwutiwes $\mathrm{S}$, Tanabe $\mathrm{K}$, Kanbara $\mathrm{H}$ : Sequence conservation in the $\mathrm{C}$-terminal part of the precursor to the major merozoite surface proteins (MSP1) of Plasmodium falciparum from field isolates. Mol Biochem Parasitol 1993, 59:95-100.

52. Manske M, Miotto O, Campino S, Auburn S, Almagro-Garcia J, Maslen G, O'Brien J, Djimde A, Doumbo O, Zongo I, Ouedraogo JB, Michon P, Mueller I, Siba P, Nzila A, Borrmann S, Kiara SM, Marsh K, Jiang H, Su XZ, Amaratunga C, Fairhurst R, Socheat D, Nosten F, Imwong M, White NJ, Sanders M, Anastasi E, Alcock D, Drury E, et al: Analysis of Plasmodium falciparum diversity in natural infections by deep sequencing. Nature 2012, 487:375-379.

53. Mu J, Myers RA, Jiang H, Liu S, Ricklefs S, Waisberg M, Chotivanich K, Wilairatana P, Krudsood S, White NJ, Udomsangpetch R, Cui L, Ho M, Ou F, Li H, Song J, Li G, Wang X, Seila S, Sokunthea S, Socheat D, Sturdevant DE, Porcella SF, Fairhurst RM, Wellems TE, Awadalla P, Su XZ: Plasmodium falciparum genome-wide scans for positive selection, recombination hot spots and resistance to antimalarial drugs. Nat Genet 2010, 42:268-271.

54. Xia ZG, Yang MN, Zhou SS: [Malaria situation in the People's Republic of China in 2011]. Zhongguo Ji Sheng Chong Xue Yu Ji Sheng Chong Bing Za Zhi. 2012, 30:419-422.

55. Dondorp AM, Yeung S, White L, Nguon C, Day NP, Socheat D, von Seidlein $L$ : Artemisinin resistance: current status and scenarios for containment. Nat Rev Microbiol 2010, 8:272-280

56. Fairhurst RM, Nayyar GM, Breman JG, Hallett R, Vennerstrom JL, Duong S, Ringwald P, Wellems TE, Plowe CV, Dondorp AM: Artemisinin-resistant malaria: research challenges, opportunities, and public health implications. Am J Trop Med Hyg 2012, 87:231-241.

57. Noedl H, Se Y, Schaecher K, Smith BL, Socheat D, Fukuda MM, Artemisinin Resistance in Cambodia 1 Study C: Evidence of artemisinin-resistant malaria in western Cambodia. N Engl J Med 2008, 359:2619-2620.

58. Phyo AP, Nkhoma S, Stepniewska K, Ashley EA, Nair S, McGready R, Ler Moo C, Al-Saai S, Dondorp AM, Lwin KM, Singhasivanon P, Day NP, White NJ, Anderson TJ, Nosten F: Emergence of artemisinin-resistant malaria on the western border of Thailand: a longitudinal study. Lancet 2012, 379:1960-1966.

59. Pumpaibool T, Arnathau C, Durand P, Kanchanakhan N, Siripoon N, Suegorn A, Sitthi-Amorn C, Renaud F, Harnyuttanakorn P: Genetic diversity and population structure of Plasmodium falciparum in Thailand, a low transmission country. Malaria J 2009, 8:155.

60. Snounou G, Viriyakosol S, Jarra W, Thaithong S, Brown KN: Identification of the four human malaria parasite species in field samples by the polymerase chain reaction and detection of a high prevalence of mixed infections. Mol Biochem Parasitol 1993, 58:283-292.

61. Brown KN, Thaithong S, Do Rosario VE, Pinheiro L, Jarra W, Zhu XP Viriyakosol S, Snounou G: High sensitivity of detection of human malaria parasites by the use of nested polymerase chain reaction. Mol Biochem Parasitol 1993, 61:315-320.
62. Hall N, Pain A, Berriman M, Churcher C, Harris B, Harris D, Mungall K, Bowman S, Atkin R, Baker S, Barron A, Brooks K, Buckee CO, Burrows C, Cherevach I, Chillingworth C, Chillingworth T, Christodoulou Z, Clark L, Clark R, Corton C, Cronin A, Davies R, Davis P, Dear P, Dearden F, Doggett J, Feltwell T, Goble A, Goodhead I, et al: Sequence of Plasmodium falciparum chromosomes 1, 3-9 and 13. Nature 2002, 419:527-531.

63. Tamura K, Peterson D, Peterson N, Stecher G, Nei M, Kumar S: MEGA5: molecular evolutionary genetics analysis using maximum likelihood, evolutionary distance, and maximum parsimony methods. Mol Biol Evol 2011, 28:2731-2739.

64. Excoffier L, Lischer HE: Arlequin suite ver 3.5: a new series of programs to perform population genetics analyses under Linux and Windows. Mol Ecol Resour 2010, 10:564-567.

65. Librado P, Rozas J: DnaSP v5: a software for comprehensive analysis of DNA polymorphism data. Bioinformatics 2009, 25:1451-1452.

66. Paul RE, Hackford I, Brockman A, Muller-Graf C, Price R, Luxemburger C, White NJ, Nosten F, Day KP: Transmission intensity and Plasmodium falciparum diversity on the northwestern border of Thailand. Am J Trop Med Hyg 1998, 58:195-203.

67. Thimasarn K, Jatapadma S, Vijaykadga S, Sirichaisinthop J, Wongsrichanalai C: Epidemiology of Malaria in Thailand. J Travel Med 1995, 2:59-65.

68. Zhou G, Sirichaisinthop J, Sattabongkot J, Jones J, Bjørnstad ON, Yan G, Cui $L$ : Spatio-temporal distribution of Plasmodium falciparum and $P$. vivax malaria in Thailand. Am J Trop Med Hyg 2005, 72:256-62.

69. Somboon P, Aramrattana A, Lines J, Webber R: Entomological and epidemiological investigations of malaria transmission in relation to population movements in forest areas of north-west Thailand. Southeast Asian J Trop Med Public Health 1998, 29:3-9.

70. Singhanetra-Renard A: Population movement, socio-economic behavior and the transmission of malaria in northern Thailand. Southeast Asian J Trop Med Public Health 1986, 17:396-405.

71. Wangroongsarb P, Sudathip P, Satimai W: Characteristics and malaria prevalence of migrant populations in malaria-endemic areas along the Thai-Cambodian border. Southeast Asian J Trop Med Public Health 2012, 43:261-269.

72. Pattaradilokrat S, Jiangbing M, Awadalla P, Su XZ: Genome diversity and applications in genetic studies of the human malaria parasites Plasmodium falciparum and Plasmodium vivax. In Malaria Parasites: Comparative Genomics, Evolution and Molecular Biology. Edited by Carlton JM, Perkins SL, Deitsch KW. Wymondham: Caister Academic Press; 2013:59-90.

73. Blackman MJ, Scott-Finnigan TJ, Shai S, Holder AA: Antibodies inhibit the protease-mediated processing of a malaria merozoite surface protein. J Exp Med 1994, 180:389-393.

74. James S, Moehle K, Renard A, Mueller MS, Vogel D, Zurbriggen R, Pluschke $G$, Robinson JA: Synthesis, solution structure and immune recognition of an epidermal growth factor-like domain from Plasmodium falciparum merozoite surface protein-1. Chembiochem 2006, 7:1943-1950.

75. Pizarro JC, Chitarra V, Verger D, Holm I, Petres S, Dartevelle S, Nato F, Longacre S, Bentley GA: Crystal structure of a Fab complex formed with PfMSP1-19, the C-terminal fragment of merozoite surface protein 1 from Plasmodium falciparum: a malaria vaccine candidate. J Mol Biol 2003, 328:1091-1103.

76. Guevara-Patino JA, Holder AA, McBride JS, Blackman MJ: Antibodies that inhibit malaria merozoite surface protein-1 processing and erythrocyte invasion are blocked by naturally acquired human antibodies. J Exp Med 1997, 186:1689-1699.

doi:10.1186/1475-2875-13-54

Cite this article as: Simpalipan et al:: Diversity and population structure of Plasmodium falciparum in Thailand based on the spatial and temporal haplotype patterns of the C-terminal 19-kDa domain of merozoite surface protein-1. Malaria Journal 2014 13:54. 